1st International Conference - Global Ethics - Key of Sustainability (GEKoS) | May 15th, 2020 | Bucharest, Romania

\title{
Quality Management in the Hotel Industry in the Macro-Regions of Romania
}

\author{
Corina Aurora MARIN (BARBU), Elena CONDREA, \\ Norina POPOVICI
}

https://doi.org/10.18662/lumproc/gekos2020/19

How to cite: Marin (Barbu), C.A., Condrea, E., \& Popovici, N. (2020). Quality Management in the Hotel Industry in the Macro-Regions of Romania. In A. Grigorescu \& V. Radu (vol. ed.), Lumen Proceedings: Vol. 11. 1 st International Conference Global Ethics - Key of Sustainability (GEKoS) (pp. 182191). Iasi, Romania: LUMEN Publishing House.

https://doi.org/10.18662/lumproc/gekos2020/19 


\title{
Quality Management in the Hotel Industry in the Macro-Regions of Romania
}

\author{
Corina Aurora MARIN (BARBU) ${ }^{1}$, Elena CONDREA2*, \\ Norina POPOVICI ${ }^{3}$
}

\begin{abstract}
The contemporary dimensions of quality management in Romania represent the fundamental means of evolution of all the agents involved in the dynamism of the market environment. Relevant in the debate of quality management in the hotel industry in Romania is the quality as a numerical and quantifiable direction in the evolution report. Quality management plays a major role in the economic science and management theory, to which is added the special attention from the tourism practices in the last years as a consequence of the direct association between quality and the satisfaction of human needs. The theory and practice of quality management in the hotel industry are accelerated and amplified with the development of society, but they are directly related to the genetic inheritance of the space, cultures, traditions, relief of Romania. The establishment of a quality service is one of the major challenges that management faces, as it is an essential condition for success in the hospitality markets in the emerging countries.
\end{abstract}

Keywords: Quality Management; hotel industry; hospitality markets; quality services.

\footnotetext{
${ }^{1}$ Bucharest University of Economic Studies, Romania, e-mail address:coribarbu@yahoo.com

${ }^{2}$ Ovidius University of Constanta, Romania, e-mail address.elenacondrea2003@yahoo.com

${ }^{3}$ Ovidius University of Constanta, Romania, e-mail address.norinapopovici@yhoo.com

* Corresponding author.elenacondrea2003@yahoo.com 


\section{Introduction}

Quality management in the hotel industry is a dynamic process that requires the application of quality management principles to all branches involved in the process, which is aimed at continuous improvement of the tools and techniques adopted by the management. [9]

The techniques adopted by the management involve the assurance of quality with constant direction in obtaining the satisfaction of the customers through an integrated system of tools, techniques and training, a system that continues to generate organizational processes that result in high quality products and techniques, where quality management guarantees the consistency of the product or the service, is responsible for an act of progress obliged to maintain a high level of excellence focused on setting major achievable goals through the progressive implementation of the quality strategy and the general course of activity for continuous innovation.

The quality becomes dominant in the management approach in the hotel industry through strategic commitments, historical and cultural realities, constructive activities, expectations from the natural environment and efforts to solve these challenges as a chance to answer. [10]

In the hotel industry an important role is played by quality management as a comprehensive approach that continues to be an inseparable part of the success and evolution of tourism focused on building quality in all aspects of the tourism process.

The technical and technological development is the core of the management activities doubled by the innovative and research activities, the design and improvement of the processes that respond to the quality management in the hotel industry and the quality management that is focused on translating the objectives, commitment, responsibility, vision, in all the existing managerial relations at the level of the hotel industry, for achieving remarkable results with a totalizable impact on all effective involvement plans.[1], [8]

The quality management in the hotel industry in Romania centered on macro-regions represents a motivation for evaluating the progress of the society, the attention that has been directed to the hospitality industry as an accepted currency in the industrialization of the economy and the currency to confirm the cultural heritage that the country has, with the help to which it can be propelled or on the contrary, a regress can occur due to the political environment unfavorable to the trading of natural resources.

The application of the principles of management in a tourist unit has effects on it, oriented especially to the satisfaction of the client that leads to the novelty with important effects materialized in economic aspects that 
contribute substantially to the national tourism, a pillar of resistance manifested in the sphere of services in the macro-regions of Romania.

\section{Literature review}

The company management is an integrated management concept for the continuous improvement of the quality of the goods and services provided by participating at all levels and functions of the organization with the help of a total quality system that is set by the plans, policies, processes, procedures, people and technology necessary for the fulfillment of the objectives. [10]

The implementation of the quality management in tourism leads to the increase of the competitive potential of the units that offer such services, changes in the organizational culture of the accommodation units, rehabilitation to the objectives pursued, the dynamics of the jobs, the increase of the satisfaction of the tourist by adapting the product to the needs, the attention paid to the environment; total quality management is focused with the help of statistical control, quality assurance system and total quality management system.

Quality management in the hotel industry becomes eligible with the help of management functions in which the importance of the existence of the five functions is vital to the entire system that claims to access a standardization of the entire tourism sector, and the function of forecasting and planning represents the beginning of an efficient management, here the plans are established, the objectives and the action programs related to the internal and external environment of the tourism sector, correlated with the experience of the management or the management team and the stage of the life cycle in which the tourist unit is located. Policy, strategy, regulations, standards, methods and procedures, budgets, forecasts, are the basic terms within the forecasting function. [9], [10]

By means of the organizational function, the delimitation of the responsibilities regarding quality, the need for financial, material, human resources as well as the combination and use of these resources on economic criteria is achieved.

The decision function and the delegation of authority brings together the managerial activities aimed at transmitting and transforming decisions into actions, specifying at the same time the tasks for the executors, the deadlines and the concrete ways of executing them.

The coordinating and coaching functions, envisages the harmonization and synchronization of all activities within the sector, as well 
as the correlation of the activity of the managers located on different hierarchical levels, including the correlation with the activity of the executives, so that all the necessary means are included, including the management of the resources to be available. at the established deadline, quantity and quality, in order to achieve the quality objectives in safe conditions.

In a quality-oriented management system, the control-evaluation function consists of all the processes through which the company's qualitative performances are measured and compared with the objectives derived from the quality policy of the organization as well as with the provisions of the standards set as benchmarks.

Quality management aims at a systematic evaluation as an element of the desired organizational culture and applied at all levels of activity: process and management system performance evaluation, periodic performance evaluation, customer satisfaction evaluation, etc. [7]

Continuous quality improvement welds all other functions necessary for the concept of quality management and recommends the ISO 9000 standard as the first systematic and internationally standardized approach to quality management in the hotel industry.

Under market economy conditions, the quality management in tourism depends on the improvement of activities, the modernization of the flow, the technology, the sustainable responsibility and the definition of the organizational characteristics.

\section{Research methodology}

The tourism industry is a dimension inherent in contemporary social life and is one of the most complex industries worldwide, involving the whole society. Having as object of study the quality management in the hotel industry in Romania, we have chosen as the barometer the numerical evolution in macro-regions of the tourist reception structures with accommodation function, with the main purpose to find out if the management quality contribution is favorable.

The data collection was done with the help of the statistical directories available at national level and the macro-regions are divided into 4 zones according to the geographical positioning of the counties so that the Macro-region 1 is represented by the North-West and Center areas; Macroregion 2 is represented by the counties located in the North-East and SouthEast; Macro-region 3 is identified with the South - Muntenia and Bucharest- 
Ilfov areas and from the Macro-region 4 the South - West Oltenia and West areas are included. [2]

The quality management in the hotel industry in the macro-regions of Romania is analyzed and tracked with the help of the numerical indicator that aims at the evolution of the tourist reception structures that are expressed in number of accommodation units. The tourist accommodation unit represents the tourism potential of the macro-regions assured with the help of quality management that generates valuable results of the tourism activity with impact at national economic level and the quantitative research can implement statistical procedures, methods that accentuate the control and the quantifiable measures of the performance.

The technological progress is the immeasurable advance that has facilitated in the last years the optimization and efficiency of the quality management with the help of indicators that allow to measure the effects of the actions and to plan an adapted strategy that characterizes the tourism activity. [4]

Qualitative research is one of the most difficult researches because it represents a dose of subjectivism on the part of the author due to the study of the contexts, the compact data that are validated by statistical methods to help the finding of the research result.

Indicators chosen to analyze the quality management are The tourist reception structures with function of tourist accommodation in macro-regions and Overnight stays in the structures of tourist reception with function of tourist accommodation in macro-regions [2]; data collection was available with the help of official data provided by the National Institute of Statistics in Romania. [6]

\section{Results}

The selected indicators are numeric dynamic elements that are the object of the national calculation and follow the accuracy of the information simultaneously with the manifestation of the conclusions that appear as a result of the application of the quality management in the hotel industry in the macro-regions of Romania.

The analysis of the tourism activity in the macro-regions between 2016 and 2019 can be quantified and expressed by the evolution of the tourist reception structures with the function of tourist accommodation and can determine the general structure of the research (Figure no.1)

Predominant from the analysis of the graphic, we can notice the upward trend in each macro-region during the studied time period, from 
which the favorable effects of the manager in the hotel industry in Romania, effects that have generated an impact on the country's economy.

Figure no.1 Evolution of the number of tourist reception structures with function of tourist accommodation in macro-regions

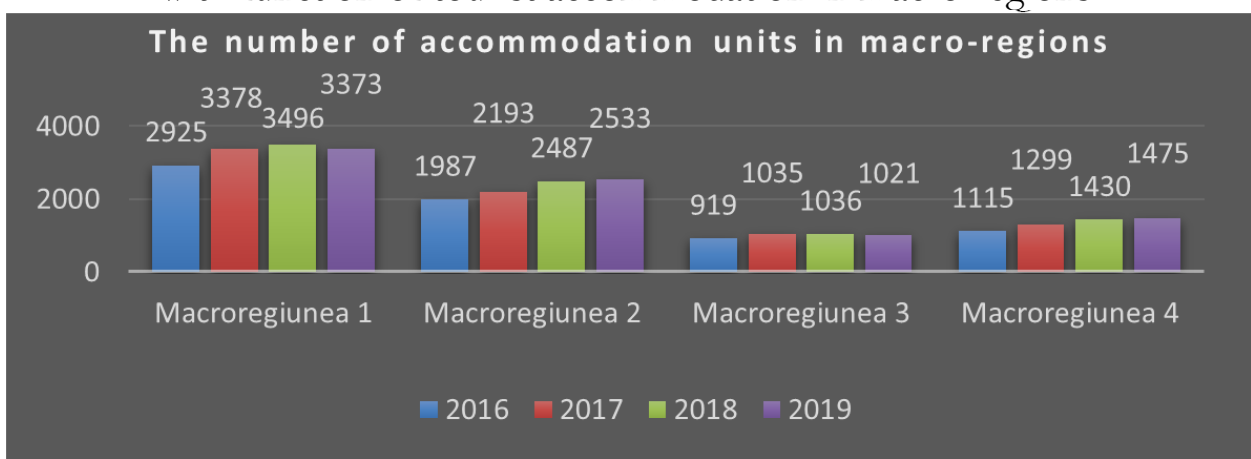

Source: made by the authors based on the data from the statistical directories

Macro-region 1 is the area with the most accommodation units in all of Romania and in 2017 their number increased by $13.41 \%$ compared to the previous year, the numerical advantage is represented by the infrastructure developed in the North-West, easy access and greater interest manifested by foreign tourists to visit the macro-region but also the faster translation of the managerial influence of tourism.

Macro-region 2 represents an important cultural hub for the country being the second macro-region with the most accommodation units, there was a 25.01\% increase in accommodation units in 2019 compared to 2016, which strengthens the efficiency of the management in the hotel industry.

One of the factors that influence the smallest number of accommodation units existing in the Macro-region 3 is the smaller area on which the macro-region extends, which is directly proportional to the tourist character of the area Macro-region 3 showed a fluctuating trend in the analyzed time period so that in 2019 it decreased by 15 accommodation units compared to the previous year.

Macro-region 4 recorded the slowest upward trend; the lack of relief units is an aspect that determines the number of accommodation units in the macro-region as compared to the other macro-regions.

It is worth mentioning that the year 2017 was the highlight for all 4 macro-regions in Romania in relation to the percentage regarding the increase in the number of accommodation units.

The analyzed indicator measures the competition and is one of the attributes that emphasize the quality in tourism necessary for the quality 
management in the hotel industry that ensures the constant change of the needs and wishes of the customers.

Overnight stays in tourist accommodation structures with function of tourist accommodation in macro-regions, represent the most relevant study tool able to give priority to a process of continuous improvement of the quality of hospitality services, aiming at excellence and profitability of the tourism sector by retaining existing guests, by exceeding their expectations, the continuous improvement of the quality, the employment, the periodic training and the ability of the service oriented personnel, the search of the best practices by comparative evaluation, and, finally, the pursuit of the accreditation of the quality by different schemes. [2], [3]

Figure no.2 Evolution of the number of overnight stays in tourist reception structures with function of tourist accommodation in macro-regions

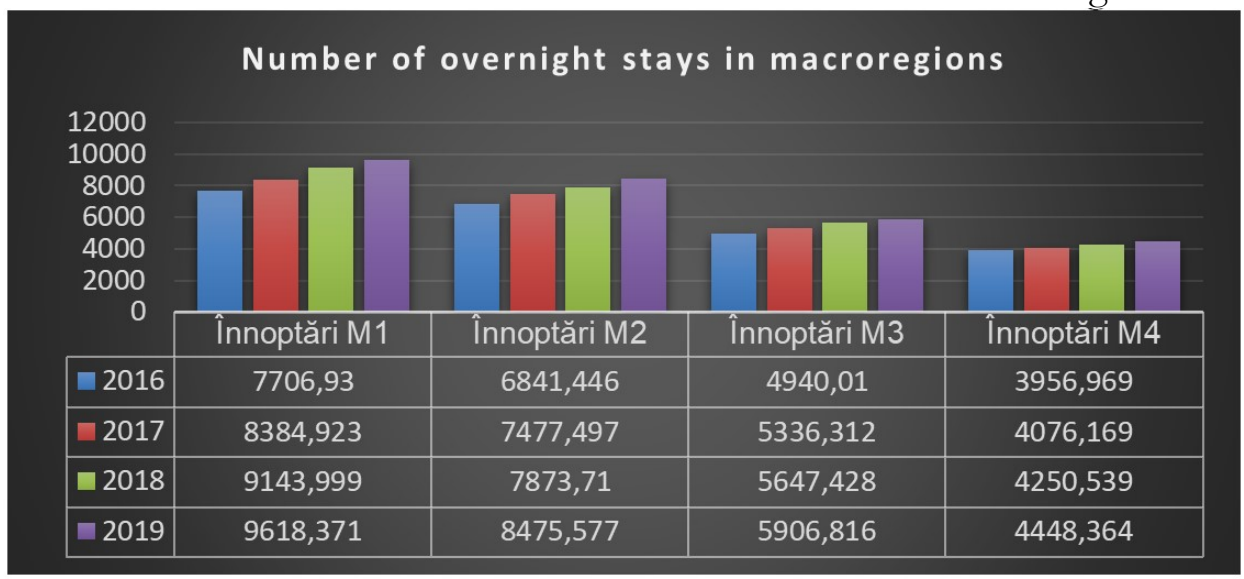

Source: made by the authors based on the data from the statistical directories *data expressed in thousands

Similar to the previously analyzed indicator, we can observe the directly proportional evolution of the number of nights in the 4 microregions and the rising trend of each of the micro-regions, which makes the main observation to take shape and realize the importance of quality management in the hotel industry in Romania.

Undoubtedly, Macro-region 1 is detached from the other macroregions, but this aspect is conferred by the relief structure that includes more tourism possibilities and attracts more foreigners due to the multiple borders existing as border crossing points. Macro-region 1 experienced an advance of the cultural promotion achieved at international level by highlighting the area of Transylvania, promotion made by prominent personalities in the international world. [5] 
Macro-region 2 shows a constant growth in the 4 years analyzed, which highlights the priority in the quality of the management in the tourist services in the macro-region. This macro-region is given major importance due to the neighbors who carry the historical emblem of our country, to which is added the uniqueness of the Danube Delta, whose effect is difficult to measure due to the difficult conditions of construction of tourist accommodation units, which is why the number of overnight stays it is not easy to quantify.

Business tourism is dominant in the quantitative analysis of the number of overnight stays in Macro-region 3, which implies the existence of intense economic activity given that this macro-region is glazed from a tourist point of view, the possibilities are limited, but transit tourism is the generator of these increases.

The number of overnight stays in the Macro-region 4, experienced a slightly increasing evolution between 2016 and 2019, this contribution realizes the tourism which is based on anthropic, economic, cultural resources and ultimately the natural ones.

Figure no.3 Percentage report of the number of units and number of overnight stays in the Romanian macro-regions in 2019
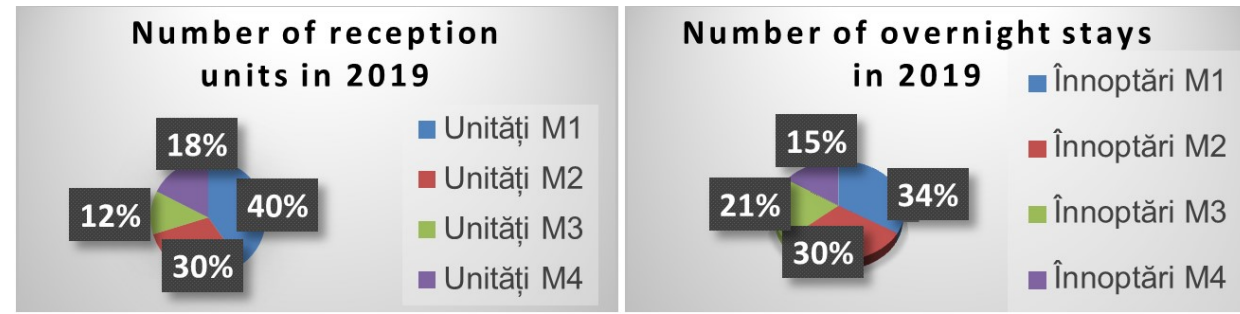

Source: made by the authors based on the data from the statistical directories

Macro-region 1 remains, still the most important tourist macroregion of Romania, so it is detached in 2019 from Macro-region 4, for 2.28 times in terms of the number of tourist reception units.

Quality management in the hotel industry in the macro-regions of Romania is an integrated branch in the services sector, ensuring an individual place in the economic-social analysis, with the help of all forms of tourism: business and personal reasons, cultural tourism, visits to relatives and friends, leisure tourism, recreation and rest, transit tourism. We consider that, at the national level, in the hotel industry in the macro-regions there is a continuous growth, occasioned by the implementation of the quality management in this industry that allows understanding the magnitude and the use of tourism at different economic, geographical and social scales. 


\section{Proposals and recommendations}

The quality of the tourist services represents a priority for the Romanian tourism correlated with the natural resources and the development potential. Special attention can be directed to the specialization of the skilled worker or managers, the explosion towards a customeroriented mentality, empathy and relationship with the needs of the tourist.

Attracting foreign investors is the recommendation to be able to keep up with the current growth rate, or even to go beyond the international vision and the flow of foreign tourists who are welcomed in a studied environment as being familiar to them.

From the point of view of the tourist resources and of the types of tourism practiced, the macro-regions are characterized by variety and heterogeneity, determined by the distribution in the territory of the relief forms, aspect for which it is proposed to carry out research studies to find tourist solutions in the seasonal areas, to highlight the agricultural areas through various national and international education projects.

It is recommended, due to the contemporary period in which we are and the amazing technological progress we are witnessing, the enrichment of the content of the touristic performance, with new types of activities, the mediation of special activities, the presence of a large typology of accommodation units that recreates the natural environment of tourists.

The change of mentality is due to a certain extent to the opening of the borders with Europe plus the rest of the continents and it is recommended the total promotion, devoid of vices having the background of a complex strategic vision, that express the degree of concordance between the expectations of the tourists and the result of the benefit thus conferring the tourist services value of use and utility, keeping the note of receptivity of the quality management.

\section{Conclusions}

The main approach was the complex analysis of the tourist reception structures and the number of overnight stays in the macro-region where we used a significant number of statistical data, correlated with cartographic materials.

Absolutely, it can be said that the upward trend of the indicators analyzed in the macro-regions of Romania has generated positive economic and image aspects, by creating new jobs, placing in a favorable image of the country, generating transit between regions, increasing the interest for 
tourism with the contribution to well-being, the improvement brought about as a result of the modernization of the means of transport and of the road and air infrastructure.

In conclusion, the appropriation of the exposed subject will contribute substantially to the analysis of frequent connections of tourism management that are poorly elucidated in relation to the macro-regions in Romania and the most relevant analysis tool can be the evolution relation of the 2 indicators analyzed previously and their role in the tourism industry.

\section{References}

[1] Cristea AA. Reconsiderarea sistemului de calitate a serviciilor din industria hotelieră românescă - premisă a creşterii competitivităţii ofertei de turism, Revista Amfiteatru Economic, Vol. XI, nr. 26, Iunie; 2009. Available from: https://www.amfiteatrueconomic.ro/temp/Articol 886.pdf [Accesed at 24 April 2020]

[2] Gogonea RM, Baltălungă AA, Nedelcu A, Dumitrescu D. Tourism Pressure at the Regional Level in the Context of Sustainable Development in Romania, Sustainabilty Journal, 9/698; 2017. [accessed at 22 April 2020]

[3] Jennings G, Nickerson N. Quality tourism experiences. United Kingdom, Oxford: Linacre House, Jordan Hill; 2005

[4] Maha A, Donici AN, Teofil PA. Electronic Tourism (E-tourism) - a theoretical approach, Munich Personal RePEc Archive MPRA Paper no. 41745 posted 14 Oct 2012 Available from: https://mpra.ub.uni-muenchen.de/41745/ [Accessed at 12 April 2020]

[5] Ministerul Dezvoltării Regionale şi Administrației Publice. Strategia Naţională pentru Dezvoltare Regională 2014-2020; 2013, pp. 119-138, Available from: http://www.inforegio.ro/images/Documente de programare/Strategia Natio nala Dezvoltare Regionala - iulie 2013.pdf, [Accessed at 10 April 2020]

[6] National Institute of Statistics, Romania, 2016-2019. Available from: http://statistici.insse.ro:8077/tempo-online/\#/pages/tables/insse-table [Accessed at 10 April 2020]

[7] Olaru M. Managementul calităţii. Bucureşti: Editura Economică; 1999

[8] Rondelli V, Cojocaru S. Managementul calităţii serviciilor din turism şi industria ospitalității. Bucureşti: Editura THR-CG; 2004

[9] Stănescu D, Mihail Ş, Stan R.. Calitatea în serviciile turistice. Bucureşti: Editura Universitară; 2009.

[10] Țuclea C, Raicu RE. Management strategic în turism-servicii. Bucureşti: Editura Uranus; 2007. 